\title{
Phenytoin silver: a new nanocompound for promoting dermal wound healing via comprehensive pharmacological action
}

\author{
Xiao-yu Ai ${ }^{*}$, Hui-juan Liu ${ }^{2 *}$, Cheng Lu ${ }^{1,2^{*}}$, Cai-li Liang ${ }^{1,2^{*}}$, Yan Sun ${ }^{3^{*}}$, Shuang Chen ${ }^{2}$, Bo Sun ${ }^{2}$, Yang Li ${ }^{1,2}$,

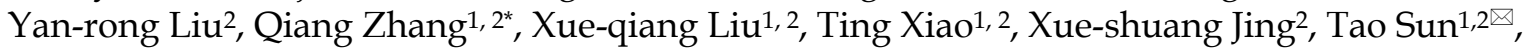 \\ Hong-gang Zhou ${ }^{1,2}$, and Cheng Yang ${ }^{1,2} \bowtie$ \\ 1. State Key Laboratory of Medicinal Chemical Biology and College of Pharmacy, Nankai University, Tianjin, China; \\ 2. Tianjin Key Laboratory of Molecular Drug Research, Tianjin International Joint Academy of Biomedicine, Tianjin, China; \\ 3. Department of Obstetrics and Gynecology, Tianjin Medical University General Hospital, Tianjin, China. \\ * Contributed equally to this study. \\ $\triangle$ Corresponding authors: Cheng Yang: cyang66_2001@yahoo.com; Tao Sun: sunrockmia@hotmail.com; Hong-gang Zhou: honggang.zhou@vip.126.com. \\ (c) Ivyspring International Publisher. This is an open access article distributed under the terms of the Creative Commons Attribution (CC BY-NC) license \\ (https://creativecommons.org/licenses/by-nc/4.0/). See http://ivyspring.com/terms for full terms and conditions.
}

Received: 2016.08.02; Accepted: 2016.10.28; Published: 2017.01.05

\begin{abstract}
Phenytoin, an antiepileptic drug, has been widely used for wound healing. Inspired by previous studies, phenytoin silver (PnAg), a sparingly soluble silver nanocompound, was synthesized which exhibited good therapeutic efficacy in tissue repair with low toxicity (LD50 $>5 \mathrm{~g} / \mathrm{kg}$ ). In vivo studies showed that $\mathrm{PnAg}$ could accelerate dermal wound healing and strong inflammation control in Sprague-Dawley rats (SD rat) and Bama minipigs. Due to its low solubility, PnAg led to low toxicity and blood enrichment in animals. Furthermore, $\mathrm{PnAg}$ could upregulate the promoter activity of Jak, Stat3, and Stat3 downstream proteins. Therefore, $\mathrm{PnAg}$ may serve as an effective therapeutic compound for wound healing through regulating the gp130/Jak/Stat3 signaling pathway.
\end{abstract}

Key words: Nanometer, phenytoin, wound healing, inflammation, Stat3.

\section{Introduction}

Wound healing is essential to prolong life and involves a complex series of interactions between different cells, cytokine mediators, and extracellular matrix (ECM) [1]. The main phases of wound healing include coagulation, inflammation, swelling, warmth, and remodeling steps. Each of these processes plays a special and essential role in wound repair $[2,3]$. A delay or absence of any one of these processes may result in delayed or even incomplete healing. The objective of wound management is to heal wounds in the shortest time with minimal pain, discomfort, and scarring.

Different methods and approaches have been developed to accelerate the healing process and prevent infection. For example, phenytoin is a sodium pump agonist with high efficiency in reducing tissue swelling [4-6] and is widely used for the treatment of convulsive disorders by influencing voltage-gated $\mathrm{Na}+$ channels $[7,8]$. Phenytoin is a classical anti-epileptic drug and has also been used for wound healing during World War II. However, it has many side effects including skin burning, dizziness, vomiting, constipation, and even leukopenia $[9,10]$. To overcome the undesirable side effects of Phenytoin, the compound PnAg was synthesized containing phenytoin anion and silver kation. Silver is a micro-soluble antimicrobial agent and was widely used in wounds to control infections $[11,12]$. So, the compound PnAg may have the combined activities of promoting wound healing and antibacterial effect. The advantage of nano fibrous PnAg is of larger surface area, which covers the 
wound area better. In vivo studies showed that PnAg accelerated wound healing in Sprague-Dawley (SD) rats and Bama minipigs with low toxicity and good resistance to infection. In vitro studies revealed that PnAg promoted proliferation of HaCaT and NIH-3T3 cells. More significantly, our work demonstrated the critical role of Stat3 pathway during the process of wound healing when treated with PnAg. Thus, PnAg promoted wound repair through gp130/Jak/Stat3 pathway. In summary, our findings suggest that PnAg is useful in wound therapy.

\section{Materials and methods}

\section{Cell lines}

Human immortalized keratinocytes cells (HaCaT), mouse embryonic fibroblast cells (NIH-3T3) and HEK293 cells were purchased from JINZIJING Company (Beijing, China). These cells were maintained in Dulbecco's minimum essential medium (DMEM)/high glucose (GIBCO, NY, USA) supplemented with $10 \%$ fetal bovine serum (FBS; Sigma-Aldrich, St Louis, USA) at $37^{\circ} \mathrm{C}$ in a humidified $5 \% \mathrm{CO}_{2}$ environment.

\section{Chemicals}

All reagents were purchased from Aldrich Chemical Co. ${ }^{1} \mathrm{H}$ NMR spectra were measured by a Bruker plus spectrophotometer at $400 \mathrm{M} \mathrm{Hz}$. IR spectra were measured on a Bio-Rad FTS 6000 spectrophotometer. TAS990 instrument was used to do atomic absorption experiment.

\section{Preparation of PnAg nanorod}

Silver ammonia solution was prepared as follows: First, $2 \mathrm{~mL}$ of $10 \%(\mathrm{w} / \mathrm{v}) \mathrm{NaOH}$ was mixed with $10 \mathrm{~mL}$ of $\mathrm{AgNO}_{3}(0.12 \mathrm{~mol} / \mathrm{L})$ at room temperature to obtain a turbid brown liquid. Then, 14 $\mathrm{mL}$ of $2 \%(\mathrm{v} / \mathrm{v}) \mathrm{NH}_{3} \cdot \mathrm{H}_{2} \mathrm{O}$ was added to the mixture until a clear solution (silver ammonia solution) appeared. Finally, $10 \mathrm{~mL}$ of phenytoin sodium (0.12 $\mathrm{mol} / \mathrm{L}$ ) was slowly added into the silver ammonia solution under ultrasonic condition at room temperature for $2 \mathrm{~h}$. The precipitate was washed with deionized water and dried under vacuum at $37^{\circ} \mathrm{C}$ for $24 \mathrm{~h}$ to obtain PnAg in the form of white solid powder. By this protocol, the yield of PnAg can reach $50 \%$. The synthesis of PnAg is depicted in Figure 1A. The chemical structure of PnAg was confirmed by ${ }^{1} \mathrm{H}$ NMR spectroscopy, IR. The fresh PnAg precipitate was suspended using $5 \%(\mathrm{w} / \mathrm{v})$ gelatin aqueous solution to detect its biological activity.

\section{Wounds preparation and treatment}

Sprague-Dawley (SD) male rats (six weeks old) and Bama minipigs (about $20 \mathrm{~kg}$ in weight) were purchased from the Animal Center of the Chinese Academy of Science (Shanghai, China). All animal studies were carried out in accordance with National Institutes of Health Animal Use Guidelines and the current Chinese Regulations and Standards for the Use of Laboratory Animals. All experimental protocols were approved by the Institutional Animal Care and Use Committee (IACUC) at Tianjin International Joint Academy of Biomedicine accordance. All animals in this experiment were well maintained. The animals were anesthetized by an intraperitoneal injection of $10 \%$ chloral hydrate $(0.3$ $\mathrm{mL} / 100 \mathrm{~g}$ ) before and during infliction of the experimental wounds. Thirty rats were randomly divided into three groups; each rat received two identical wounds $\left(3 \mathrm{~cm}^{2}\right)$ on its back. The control drug used in this experiment was gelatin silver (China Food and Drug Administration), which is nano particulate silver gel that have a broad-spectrum antibacterial activity [13]. In all three groups, one wound of each rat was treated with silver gelatin, whereas PnAg was applied on the second wound. In groups 1 and 2, the rats were sacrificed on day 7 and 17 respectively and wounded skin tissues were used for pathological examination. Rats in group 3, on the other hand, were sacrificed after 24 days to observe the wound healing process for a long period. Similar wound healing experiments were also performed in Bama minipigs. A total of six animals were used in the experiment with each Bama minipig receiving six round full thickness skin excisions of $7 \mathrm{~cm}^{2}$ in size on its back. Six excision wounds were divided into three groups. One wound in each group was used as a control and treated with silver gelatin and the second wound was treated PnAg. The animals were sacrificed and skin wounds were collected and analyzed by pathological examination on day 7 in group 1 and day 17 in group 2, whereas wound healing was observed for 24 days in group 3. Silver gelatin was used at the dose of $0.1 \mathrm{~g} / \mathrm{kg}$ (Shenzhen Yuanxing Pharmaceutical Co., Ltd, China, $0.35 \mathrm{~g} / \mathrm{g}$ ) and PnAg was used at the dose of $0.25 \mathrm{~g} / \mathrm{kg}$ $(0.05 \mathrm{~g} / \mathrm{mL})$. All treatments were regularly applied every two days, and the wounds were visually inspected and photographed every day. The areas of wounds were measured and then calculated using the equation for an ellipse: $\left(\right.$ An $($ Arean $\left.)=n r_{1} r_{2}\right)$ [11].

To examine the anti-infective effect of PnAg, each of 10 rats was subjected to three round full-thickness skin excisions of $3 \mathrm{~cm}^{2}$ in size on their backs and the wounds was treated with Staphylococcus aureus $\left(100 \mu \mathrm{L}, 1 \times 10^{4} \mathrm{cfu} / \mathrm{mL}\right)$ after wounding. The first wound was treated with chitosan gel $0.1 \mathrm{~g} / \mathrm{kg}$ (Guo Chuang biological technology Co., Ltd., Jilin, China), the second was treated with PnAg 
$0.25 \mathrm{~g} / \mathrm{kg}(0.05 \mathrm{~g} / \mathrm{mL})$ while gelatin $(5 \%)$ was applied

to the third wound.

\section{Immunohistochemistry}

The available wound tissue sections were deparaffinized and rehydrated. Subsequently, 3\% $\mathrm{H}_{2} \mathrm{O}_{2}$ in methanol was used for $10 \mathrm{~min}$ to block endogenous peroxidase activity. After boiling in 0.01 $\mathrm{mol} / \mathrm{L}$ citric acid solution for $20 \mathrm{~min}$ to retrieve the antigen, normal goat serum was applied at $37^{\circ} \mathrm{C}$ for $10 \mathrm{~min}$. The sections were treated with the following primary antibodies: collagen I (Affinity, Changzhou, China), NF-kB (Affinity, Changzhou, China), MMP-2 (Affinity, Changzhou, China), MMP-9 (Affinity, Changzhou, China), and TGF- $\beta$ (Affinity, Changzhou, China). After incubation for $1 \mathrm{~h}$, sections were washed with phosphate-buffered saline (PBS) and incubated with biotinylated goat anti-mouse IgG antibody (Zhongshan Biology Technology Co., Ltd., Beijing, China) at $37^{\circ} \mathrm{C}$ for $30 \mathrm{~min}$. Following staining with 3 , 3 '-diaminobenzidine $(\mathrm{DAB}) / \mathrm{H}_{2} \mathrm{O}_{2}$ and $\mathrm{HE}$, sections were cleared and mounted for observation and analysis.

\section{Acute toxicity testing}

Six rats (SD rats, about $180 \mathrm{~g}$ in weight) were anesthetized by an intraperitoneal injection of $10 \%$ chloral hydrate $(0.3 \mathrm{~mL} / 100 \mathrm{~g})$. Each rat was subjected to four rounds of full-thickness skin excisions on its back at the size of $3 \mathrm{~cm}^{2}$. The excision was extended deeper throughout the dermis into subcutaneous tissue. All wounds were treated with $\mathrm{PnAg}(5 \mathrm{~g} / \mathrm{kg}$, $0.5 \mathrm{~g} / \mathrm{mL}$ ) for 14 days. The control groups were treated with therapeutic dose $0.25 \mathrm{~g} / \mathrm{kg}(0.05 \mathrm{~g} / \mathrm{mL}) \mathrm{PnAg}$. At the end of the treatment, rats were sacrificed and blood plasma was harvested to detect the concentration of silver by inductively coupled plasma mass spectrometry (ICP-MS).

\section{Cell viability assay}

The effect of PnAg was detected by MTT assay, which is widely used for assessing cell metabolic activity and to measure cytotoxicity or cytostatic activity of potential medicinal agents. HaCat and NIH3T3 cells were seeded in a 96-well plate and treated with PnAg at different concentrations. PnAg was first dissolved in DMSO $(100 \mathrm{mM})$, and then diluted with culture medium (The final concentration for NIH-3T3 is $0.16,0.32,0.64,1.25,2.5,5,10$ and 20 $\mu \mathrm{M}$ and for HaCat is $0.32,0.64,1.25,2.5,5,10,20$ and $40 \mu \mathrm{M})$. The solution of PnAg was then added to the cells directly. The control group was treated with solvent. At $48 \mathrm{~h}$, cell viability was measured by MTT (3-(4,5-dimethylthiazol-2-yl)-2,5-diphenyltetrazolium bromide) assay.

\section{Bacteriostasis experiments}

Bacteriostatic activity of PnAg against Escherichia coli, Staphylococcus aureus, and Pseudomonas aeruginosa was tested by bacteriostasis experiments. These bacteriums were homogenously plated onto plates. The filter papers were cut into $1 \mathrm{~cm}$ pieces using a paper punch. PnAg was dissolved using 5\% (w/v) gelatin aqueous solution at a final concentration of 0.1 $\mathrm{g} / \mathrm{mL}$. The amount of saturated water absorption of the filter paper with the diameter of $1 \mathrm{~cm}$ was about $0.25 \mathrm{~mL}$. Sterilized circular filter paper pieces with PnAg were placed on the plates containing bacteria. For control experiments, the paper pieces soaked with sterile distilled water were placed in the plates containing bacteria. The diameters of inhibition zones were measured to test the bacteriostatic function of PnAg.

\section{Western blot}

NIH-3T3 and HaCaT cells were treated with 1.5 $\mu \mathrm{M}$ and $20 \mu \mathrm{M}$ PnAg separately for $48 \mathrm{~h}$. The control groups were treated with only solvent $(0.1 \%$ DMSO in PBS). Subsequently, the cells were harvested and the proteins were extracted by using RIPA buffer (Beyotime, Jiangsu, China). Proteins were separated by electrophoresis and transferred onto polyvinylidene difluoride membranes (Millipore, Bedford, MA, USA). Membranes were blocked and incubated with primary antibodies; GAPDH was used as an internal control. After incubation with HRP-conjugated goat anti-mouse secondary antibody (Santa Cruz, CA, USA), the proteins were visualized by an enhanced chemiluminescence kit (Amersham Corp, Buckinghamshire, United Kingdom) and exposed to chemiluminescent film.

\section{Zymography assay}

MMP-2 and MMP-9 activities were analyzed by zymography assays. The harvested proteins were separated in 10\% SDS-PAGE gel containing collagen enzyme substrates. After electrophoresis, gels were equilibrated and incubated in $50 \mathrm{mM}$ Tris- $\mathrm{HCl}(\mathrm{pH}$ 7.5), $10 \mathrm{mM} \mathrm{CaCl}_{2}, 150 \mathrm{mM} \mathrm{NaCl}, 1 \mathrm{mM} \mathrm{ZnCl}$, and $0.02 \% \mathrm{NaN}_{3}$ for $40 \mathrm{~h}$ at $37{ }^{\circ} \mathrm{C}$. After staining with Coomassie R250, gels were destained until apparent zones associated with MMP activity appeared clearly.

\section{Data Statistical analysis}

All results were shown in the format of mean \pm standard deviation. The values were analyzed by one-way ANOVA, followed by Bonferroni post hoc test (SPSS software package version 17.0; SPSS Inc., Chicago, IL). The level of statistically significant difference was set at $\mathrm{P}<0.05$. 


\section{Results}

\section{The chemical and morphology characterization of PnAg nanorod}

The synthetic route is shown in Figure 1A. The chemical structure identification data of PnAg was provided by ${ }^{1} \mathrm{H}$ NMR spectroscopy and IR: ${ }^{1} \mathrm{H}$ NMR (400 MHz, DMSO-d $\mathrm{d}_{6}, \delta$ ppm): $7.35(\mathrm{~m}, 10 \mathrm{H}), 9.30$ (s, $1 \mathrm{H}), 11.09$ (s, $1 \mathrm{H})$; IR (KBr, cm$\left.{ }^{-1}\right): 3587,3209,3059$, 2808, 2499, 2156, 1695, 1639, 1601, 1493, 1373, 1269, 1076, 988, 760, 698, and $536 \mathrm{~cm}^{-1}$. Full spectra are given in supplementary data. The result of atomic absorption shows that the content of silver in the product is $31.2 \%$.

Figure 1B shows the morphology $\mathrm{PnAg}$, which is like nanorod. The diameter and the length of the nanorod is about $50 \mathrm{~nm}$ and $400 \mathrm{~nm}$ separately. The DLS data showed that the intensity of PnAg was under 700nm (Fig 1C). The imaging results of HEK293 cells treated with PnAg and displayed in Fig 1D show that PnAg promoted junction formation and rapid proliferation in HK293 cells thus affording the possibility to improve wound healing.

A<smiles>O=C1N=C(O[Na])NC1(c1ccccc1)c1ccccc1</smiles>

B
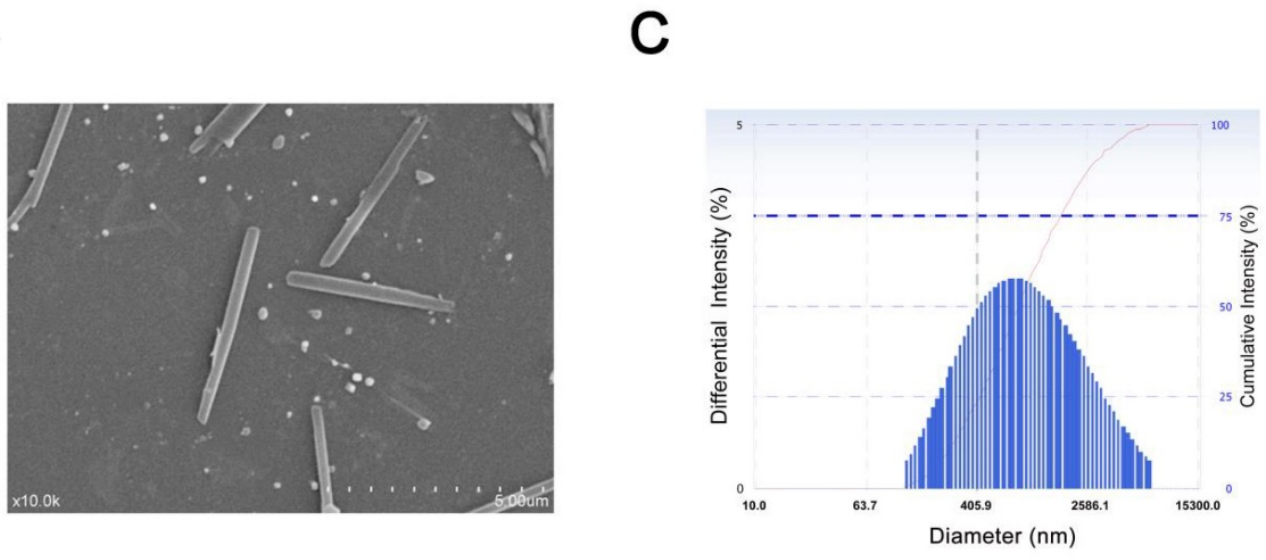

D
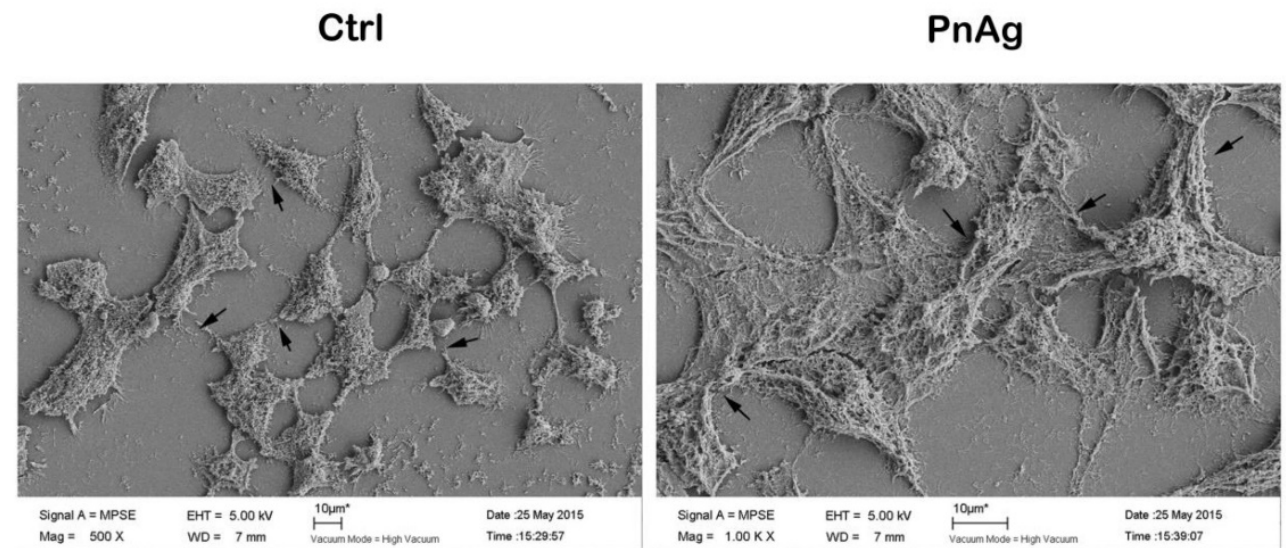

Figure 1. The characterization of PnAg morphology. (A) Synthesis of PnAg. (B) The SEM image of PnAg nanorod. (C) DLS results of PnAg nanorod. (D) The SEM images of HEK293 cells treated with silver gelatin and PnAg. 
A

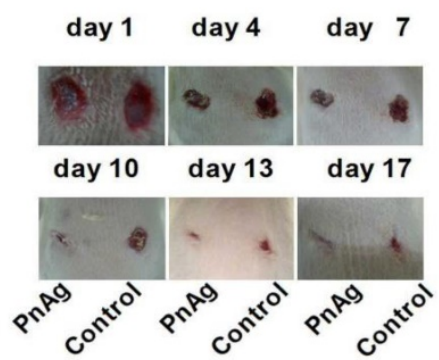

C

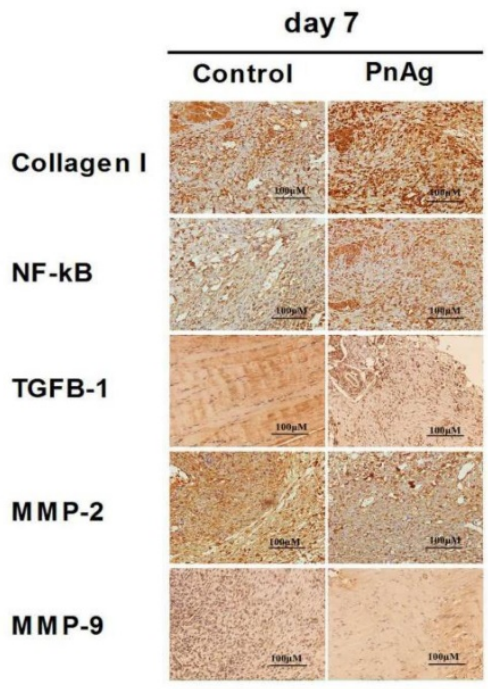

E

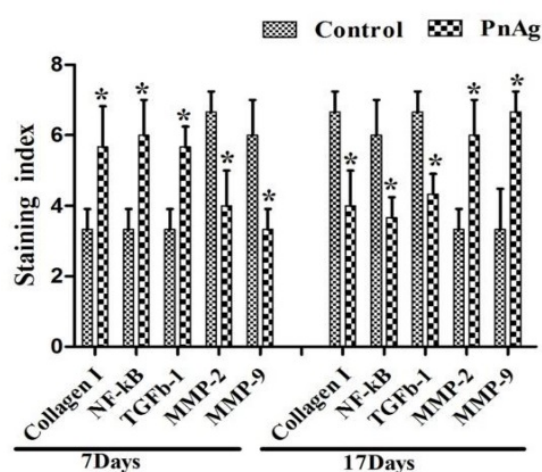

B

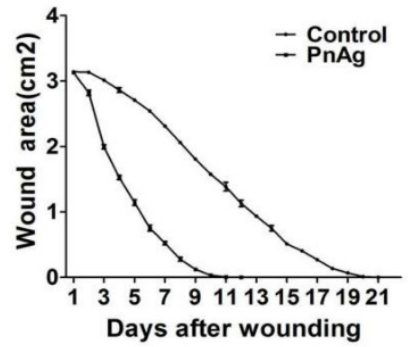

D

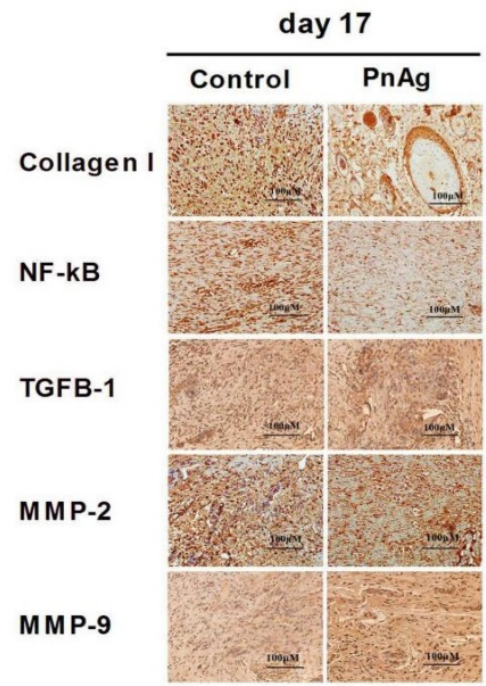

F

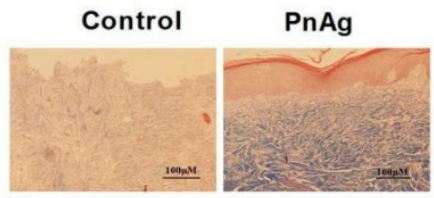

G

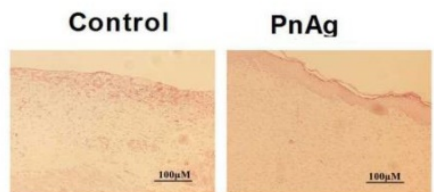

Figure 2. PnAg promotes wound healing in SD rats. (A) Photographs of rat skin full-thickness excision wounds on different post-excision days. (B) Change in wound areas of SD rats after treatment; (C) and (D) Expression levels of collagen I, NF-KB, TGF-B, MMP-2, and MMP-9 in tissues on day 7 and 17 detected by immunohistochemistry. (E) Histogram of protein expression levels in these tissues. (F) and (G) Histomorphological changes in wound tissues stained by Masson trichrome and $\mathrm{HE}$ on day 17.

\section{PnAg promotes wound healing in vivo}

Skin injury models of SD rats and Bama minipigs were treated with PnAg and silver gelatin as the control to determine the potential effects of PnAg on wound healing. As shown in Figs. 2A, 2B, Figs. 3A, and $3 \mathrm{~B}$, the wound areas in PnAg-treated groups were smaller than those in control groups. Also, wounds in PnAg groups were almost completely healed by 13-17 days, however, the same level of wound healing took 20-25 days in control groups. After the animals had been sacrificed, wound tissues were stained with $\mathrm{HE}$ and Masson trichrome (Figs. 2F, 2G, Figs. 3C, and 3D). The results of fibroblasts cells, collagen fibers, and new blood vessels indicated that PnAg-treated SD rats and Bama minipigs exhibited significant and fast recovery. The wounds in control animals showed fewer newly formed micro-vessels and fibroblasts. 
Furthermore, a lot of necrotic tissue could be seen in the wound and thin granulation tissue layers were detected in the control group. Thus, our results clearly indicated that PnAg could effectively organize fibroblast cells, collagen fibers, and blood vessels and promote the healing of wounds.

\section{PnAg selectively regulates the expression levels of collagen I, NF-kB, TGF- $\beta$, MMP-2, and MMP-9 at different healing times}

Immunohistochemistry was employed to analyze the expression levels of collagen I, NF- $\mathrm{kB}$, TGF- $\beta$, MMP-2, and MMP-9 in animals at day 7 and 17 after PnAg treatment. The expression levels of collagen I, NF-KB, and TGF- $\beta$ were upregulated at day 7 but downregulated at day 17 compared with the control group. On the contrary, the expression levels of MMP-2 and MMP-9 were upregulated at day 17. Thus, inflammation-related genes were upregulated in the early stage after PnAg treatment, whereas MMP2 and MMP9 were upregulated in the epithelial formation stage.

\section{PnAg exhibits anti-infective effect during wound healing}

The ability to fight infection is a critical feature for any drug used for wound repair. We determined the role of PnAg in inhibiting infection after injury using chitosan as the positive control. During the healing process, PnAg significantly reduced the incidence of wound infection as evidenced by less amount of pus and blood compared with chitosan-treated groups (Fig. 4A). Furthermore, wound healing was faster and the wound areas were smaller at multiple time points in the PnAg-treated groups when compared to the control groups treated with chitosan (Figs. 4B and C). The bacteriostasis experiment also showed that PnAg could quickly inhibit E. coli, S. aureus, and $P$. aeruginosa infections (Fig. 4D and 4E).

\section{PnAg has low toxicity and low concentration in blood}

Six rats were used to test the toxicity of PnAg at 5 $\mathrm{g} / \mathrm{kg}$. No abnormal animal behavior or death was observed during the entire experimental period. The blood of the sacrificed animals was collected and analyzed using HPLC and ICP-MS. In HPLC experiments, no peak was observed at the position of the standard phenytoin (Fig. 5B). ICP-MS results indicated that silver concentration in plasma was $58.18 \mu \mathrm{g} / \mathrm{L}$ (Fig. 5C).
A

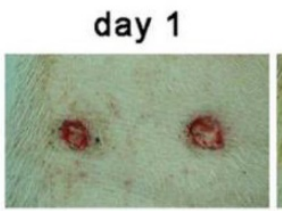

day 4

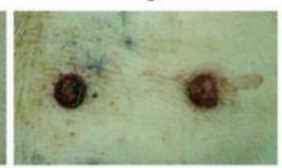

day 14

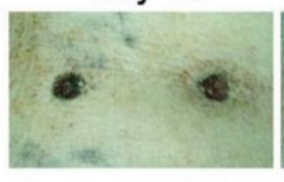

Control PnAg

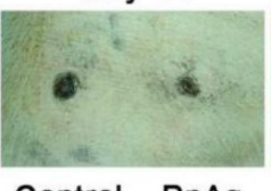

Control
PnAg

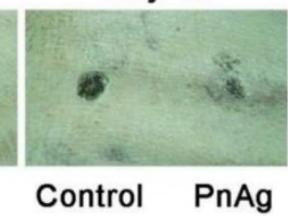

day 7

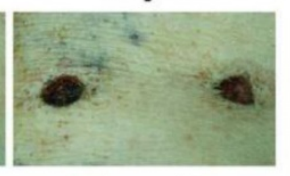

day 17

PnAg
B

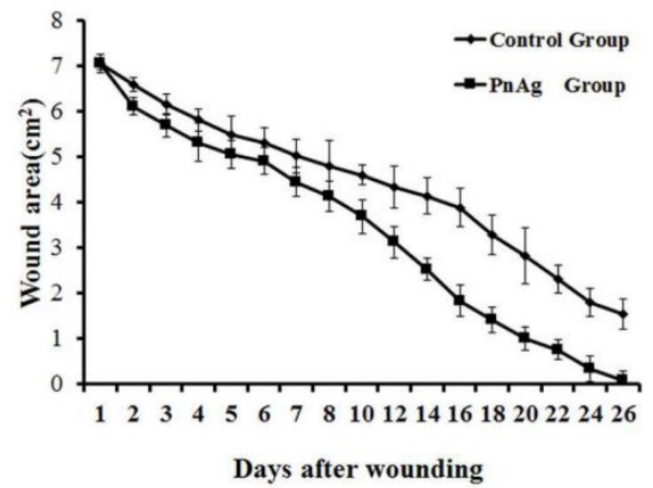

D

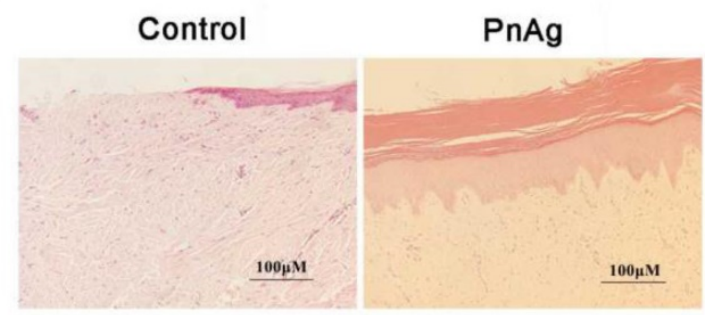

Figure 3. PnAg promotes wound healing in the Bama minipig model. (A) Photographs of skin full-thickness excision wounds of the control (sliver gelatin) and $\mathrm{PnAg}$ groups. (B) Wound areas at different days. (C) HE staining and (D) Masson trichrome staining were performed to analyze the histomorphological changes of wound tissues on day 17. 
A

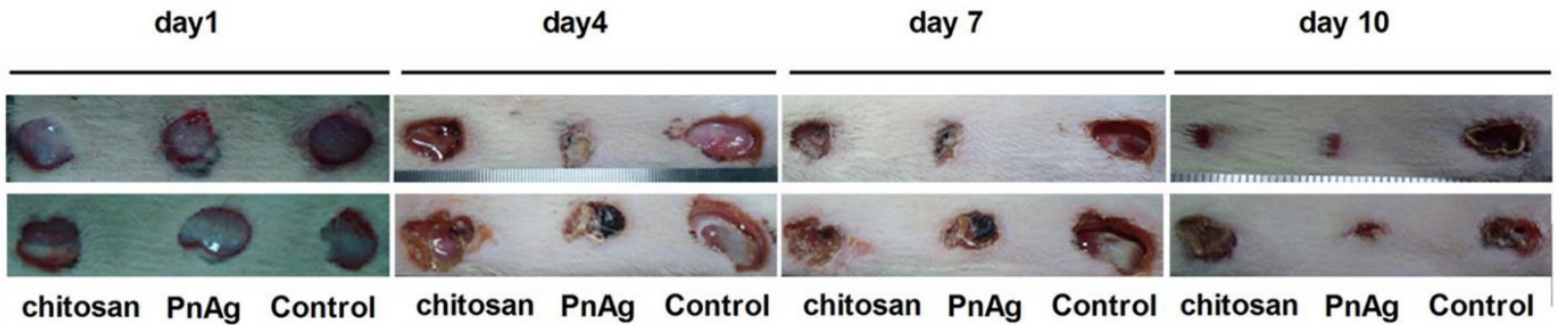

B

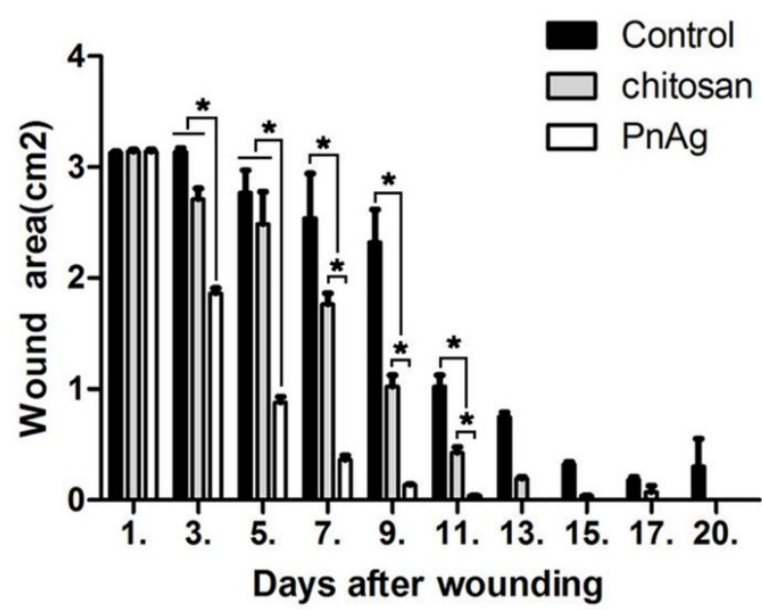

D

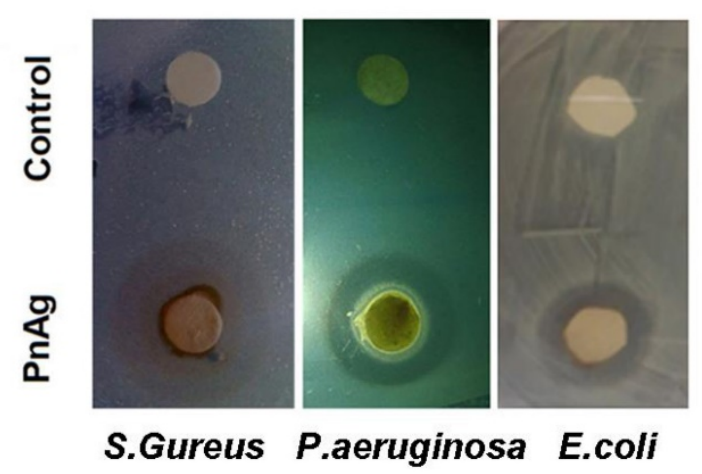

C

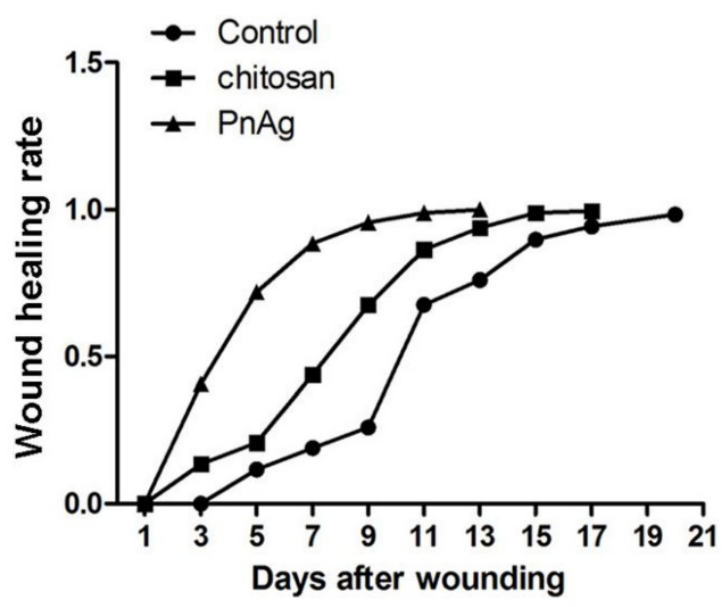

E

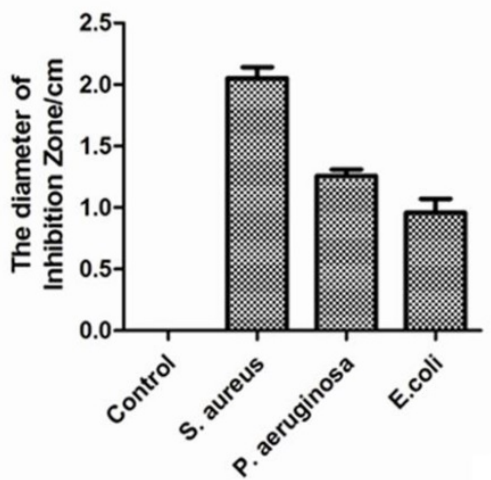

Figure 4. PnAg has wound healing and anti-infection function. After skin excisions, Wounds were treated with PnAg, chitosan as the positive control, and gelatin as the blank control. (A). Photographs of the progression of wound areas; (B) Change in wound areas when treated with PnAG, Chitosan, or gelatin; (C) The ratio of skin recovery; (D) In vitro antibacterial ability of $\mathrm{PnAg}$ against Escherichia coli, Staphylococcus aureus, and Pseudomonas aeruginosa; (E) Histogram of plaque diameters.

\section{PnAg promotes NIH-3T3 and HaCat cell proliferation and regulates Jak/Stat3 pathway}

Fibroblast cells (NIH-3T3) and epidermal cells (HaCat) were used to elucidate the mechanism of PnAg in wound healing. Cells were treated with PnAg at different concentrations. $48 \mathrm{~h}$ after treatment, MTT was performed to examine the effect of PnAg on $\mathrm{HaCaT}$ and NIH-3T3 cell viability (Figs. 6A and 6B). Results showed that low level of PnAg could increase cell viability, which is similar to the results of their promotion on cell-cell junction. However, high doses of the PnAg resulted in cytotoxicity, which leading to a decrease in cell viability. In wound healing assay, NIH-3T3 and HaCaT Cells migration ability was tested at different time points after treated with PnAg. The results showed that PnAg accelerated cell migration (Fig 6C). To understand the interaction between PnAg and its targeting proteins, molecular docking was used. Here we used the crystal structure 
of the entire extracellular portion of human gp130 (PDBID: 3L5H, Domains 1 to 6, D1-D6), which is the first atomic resolution structure of the complete ectodomain of any "tall" cytokine receptor. The binding pocket was reported in the D2 and D3 domain of gp130. D2-D3 domain was a cytokine-binding module and has a ligand binding region which has been reported to bind different ligands [14]. The molecular structure of phenytoin-Ag was docked into this binding pocket. We observed that PnAg could interact with Arg25 and Glu27 in the active pocket of gp130 (Fig. 6D). To further confirm this, zymography and Western blotting were performed to identify the downstream proteins of gp130. The results showed that MMPs activities and the protein expression levels of Stat3, collagen I, TGFB1, and VEGF were higher after PnAg treatment (Figs. 6E and 6F). These findings provide a molecular basis for understanding the function of PnAg in wound healing. After PnAg treatment, the increased activity of Stat3 resulted in the upregulation of its downstream proteins, collagen I, TGFB1, and VEGF.
These proteins play critical roles in the proliferation and inflammation control of wound healing (Fig. 6G).

\section{Discussion}

Wound repair is often characterized by prolonged inflammation, faulty re-epithelialization, and poor matrix remodeling. Silver has been shown to be an antibacterial agent, which can provide a sanitary environment for the wound healing $[15,16]$. In this study, we have provided evidence that PnAg can effectively function to accelerate wound healing and reduce traumatic area compared with the control groups in SD rat and Bama minipig skin injury models. Furthermore, during the entire healing progress, PnAg reduced the incidence of wound infection with less pyaemia compared with the prositive control, chitosan, which has obvious inhibitory activity on Escherichia coli, Staphylococcus aureus, Candida albicans and other pathogenic microbe [17]. -treated group used as a control. These findings clearly suggested that PnAg is a desirable agent to control infection during wound recovery.

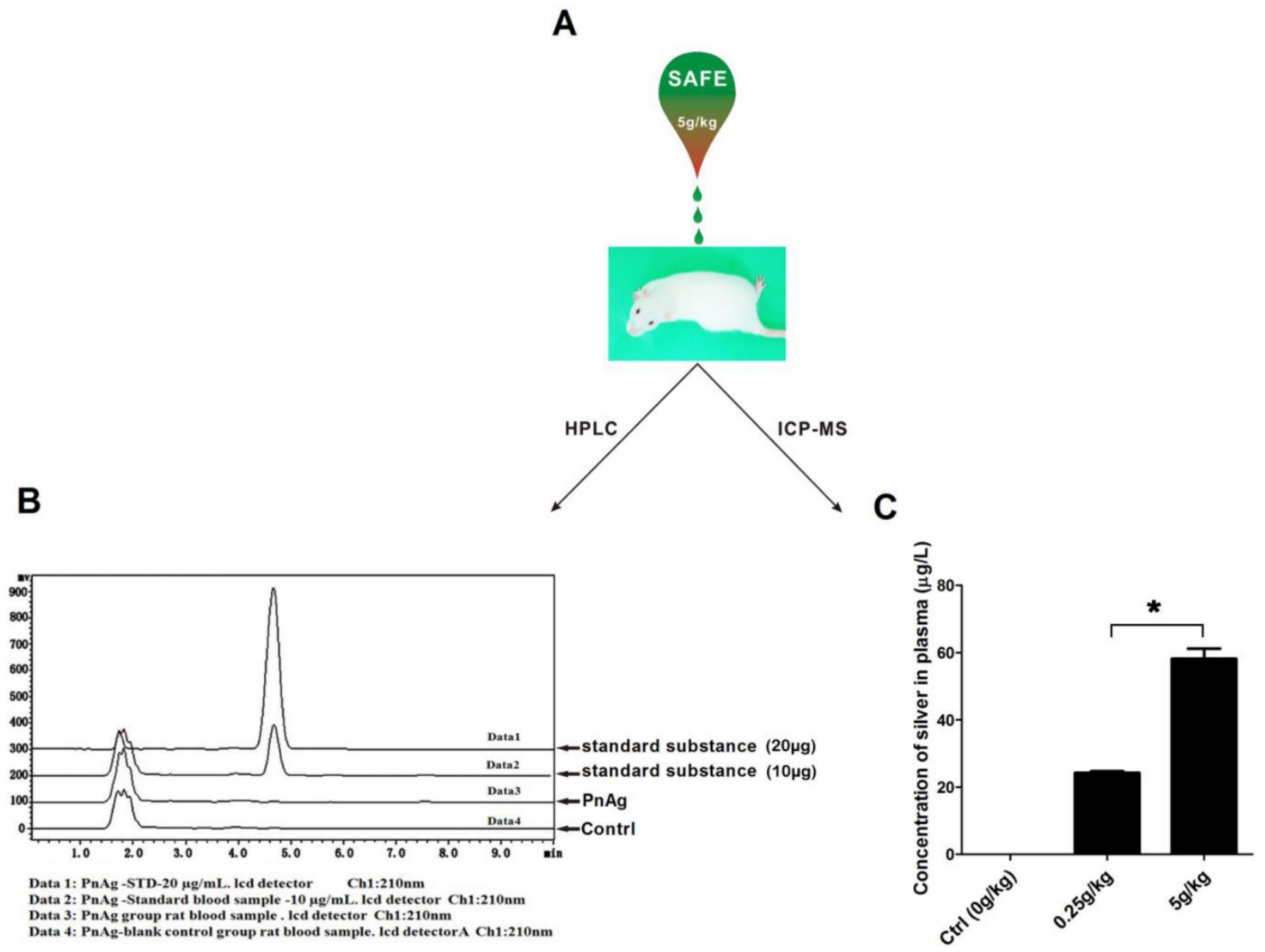

Figure 5. PnAg is safe and effective in treating wounds; (A) Rats were treated with PnAg at the cumulative dosage of $5 \mathrm{~g} / \mathrm{kg}$ in the wound area during the acute toxicity test. (B) and (C) HPLC and ICP-MS analysis results of Blood samples of the sacrificed animals. 
A

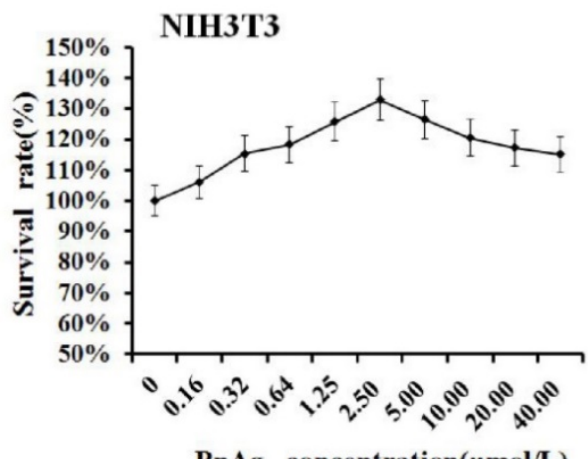

C
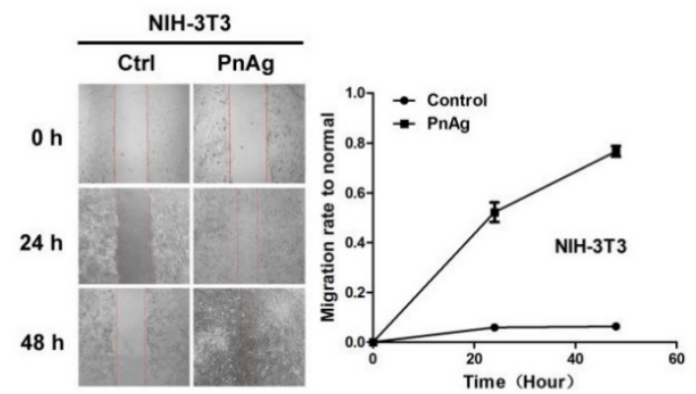

D

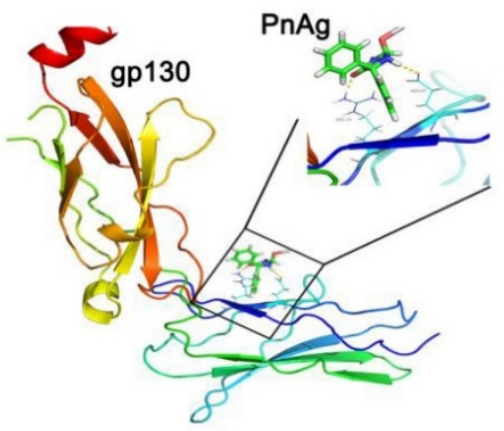

$\mathbf{F}$

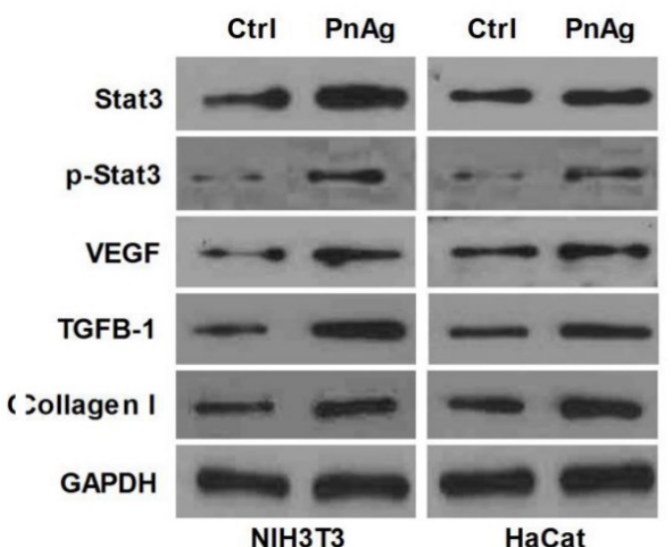

B

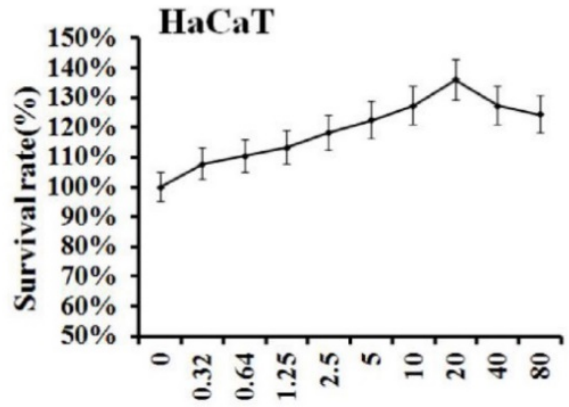

PnAg concentration $(\mu \mathrm{mol} / \mathrm{L})$

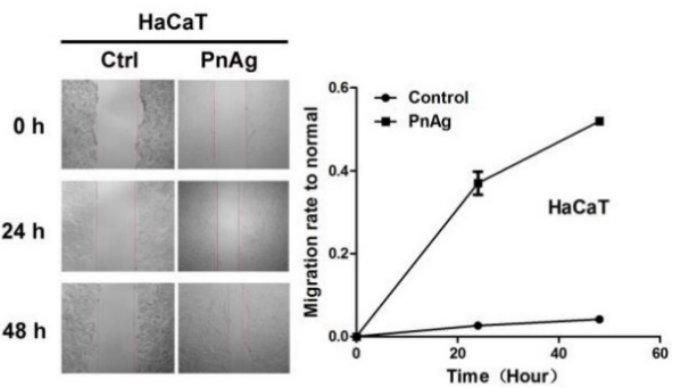

E

\section{Ctrl PnAg Ctrl PnAg}

MMP2

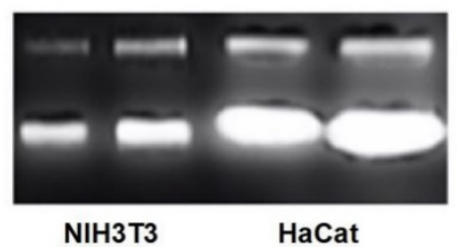

G

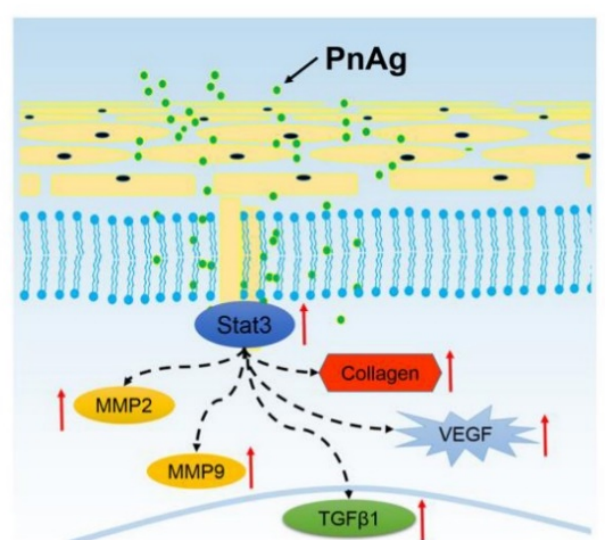

Figure 6. PnAg regulates gp 130/Jak/Stat3 signaling pathway (A) and (B) NIH-3T3 and HaCat Cells were treated with PnAg at different concentrations and cell viability was tested using MTT analysis. (C) Wound healing assay reflected the effect of $\mathrm{PnAg}$ on cell migration. (D) Binding mode of PnAg in the active pocket of gP130. (E) and (F) MMPs activity and expression levels of Stat3, VEGF, TGFB-1, and TGFB1 detected using zymographic and Western blot assays. (G) Diagram of the proposed function of $\mathrm{PnAg}$ in wound inflammation and re-epithelialization controls. 
Skin wound healing requires a complex interplay of cells and ECM [18]. Inflammation control and re-epithelialization are the most important processes during wound healing. In this respect, $\mathrm{NF}-\mathrm{kB}$ is a key nuclear transcription factor that regulates many types of genes governing immune and inflammatory responses [19, 20]. Certain pro-inflammatory cytokines, such as IL-1a, IL-2, NO, and TNF- $\alpha$, are transcriptionally regulated by NF- $\mathrm{KB}$ [21-23]. Recent studies also suggested that NF-kB also has a tissue-protective function in wound healing [24, 25]. In the present study, the expression levels of NF- $\mathrm{kB}$ and TGF- $\beta$ were increased at the early stage of wound healing after PnAg treatment. In the re-epithelialization stage, epidermal epithelial cells need to migrate into the wound bed, and collagen-based scar tissue replaces the fibrin matrix [26-28]. MMPs are extracellular proteases capable of cleaving most ECM components and proteolytically modifying many signaling proteins which are important for wound healing [29-32]. Collagen is a natural substrate for cellular attachment, growth, and migration [33]. In this study, both MMPs and collagen were activated by PnAg during the re-epithelialization stage.

Molecular mechanisms underlying the accelerated wound healing by PnAg were studied in vitro using NIH-3T3 and HaCaT cells. Our results clearly showed that PnAg could increase HaCaT and NIH-3T3 cell proliferation. Furthermore, treatment with PnAg in vitro activated the Jak/Stat3 pathway, as well as strongly upregulated the expression of VEGF, TGFB-1, and collagen I. It appears that PnAg could accelerate wound healing through the gp130/Jak/Stat3 signaling pathway. In vivo experiments demonstrated that PnAg could promote wound healing in SD rats and Bama minipigs with low scar formation. Thus, our study illustrated the desirable efficacy, low toxicity, and negligible blood enrichment of PnAg during wound healing. We have provided clear evidence for the potential use of PnAg as a therapeutic nanochemical compound in wound healing.

\section{Supplementary Material}

Supplementary figures and tables.

http://www.thno.org/v07p0425s1.pdf

\section{Acknowledgments}

This study was supported by the National Natural Science Funds of China [Grants 81201650 and 81572838], the Key Technologies R\&D Program of Tianjin [Grant 11ZCKFSY06900], Tianjin Natural Science and Technology Fund [Grant 15JCYBJC26400], and Foundation for the Author of
National Excellent Doctoral Dissertation of China [Grant 201482].

\section{Competing Interests}

The authors have declared that no competing interest exists.

\section{References}

1. Kant V, Gopal A, Pathak NN, Kumar P, Tandan SK, Kumar D. Antioxidant and anti-inflammatory potential of curcumin accelerated the cutaneous wound healing in streptozotocin-induced diabetic rats. Int Immunopharmacol. 2014; 20: 322-30.

2. MacKay D, Miller AL. Nutritional support for wound healing. Altern Med Rev. 2003; 8: 359-77.

3. Janis JE, Harrison B. Wound Healing: Part I. Basic Science. Plast Reconstr Surg. 2016; 138: 9S-17S.

4. Anstead GM, Hart LM, Sunahara JF, Liter ME. Phenytoin in wound healing. Ann Pharmacother 1996; 30: 768-75.

5. Meena K, Mohan AV, Sharath B, Somayaji SN, Bairy KL. Effect of topical phenytoin on burn wound healing in rats. Indian J Exp Biol. 2011; 49: 56-9.

6. Firmino F, de Almeida AM, e Silva Rde J, Alves Gda S, Grandeiro Dda S, Penna LH. [Scientific production on the applicability of phenytoin in wound healing]. Rev Esc Enferm USP. 2014; 48: 166-73.

7. Molnar P, Erdo SL. Vinpocetine is as potent as phenytoin to block voltage-gated $\mathrm{Na}+$ channels in rat cortical neurons. Eur J Pharmacol. 1995; 273: 303-6.

8. Shin HW, Youn YC. Neuroleptic malignant syndrome induced by phenytoin in a patient with drug-induced Parkinsonism. Neurol Sci. 2014; 35: 1641-3.

9. Modaghegh S, Salehian B, Tavassoli M, Djamshidi A, Rezai AS. Use of phenytoin in healing of war and non-war wounds. A pilot study of 25 cases. Int J Dermatol. 1989; 28: 347-50.

10. el Zayat SG. Preliminary experience with topical phenytoin in wound healing in a war zone. Mil Med. 1989; 154: 178-80.

11. Aziz Z, Abu SF, Chong NJ. A systematic review of silver-containing dressings and topical silver agents (used with dressings) for burn wounds. Burns. 2012; 38: 307-18

12. Hebeish A, El-Rafie MH, El-Sheikh MA, Seleem AA, El-Naggar ME. Antimicrobial wound dressing and anti-inflammatory efficacy of silver nanoparticles. Int J Biol Macromol. 2014; 65: 509-15.

13. Halder D, Mitra A, Bag S, Raychaudhuri U, Chakraborty R. Study on gelatin-silver nanoparticle composite towards the development of bio-based antimicrobial film. J Nanosci Nanotechnol. 2011; 11: 10374-8.

14. Xu Y, Kershaw NJ, Luo CS, Soo P, Pocock MJ, Czabotar PE, et al. Crystal structure of the entire ectodomain of gp130: insights into the molecular assembly of the tall cytokine receptor complexes. J Biol Chem. 2010; 285: 21214-8

15. Archana D, Singh BK, Dutta J, Dutta PK. Chitosan-PVP-nano silver oxide wound dressing: in vitro and in vivo evaluation. Int J Biol Macromol. 2015; 73: 49-57.

16. Aubert-Viard F, Martin A, Chai F, Neut C, Tabary N, Martel B, et al. Chitosan finishing nonwoven textiles loaded with silver and iodide for antibacterial wound dressing applications. Biomed Mater. 2015; 10: 015023.

17. Dai T, Tanaka M, Huang YY, Hamblin MR. Chitosan preparations for wounds and burns: antimicrobial and wound-healing effects. Expert Rev Anti Infect Ther. 2011; 9: 857-79.

18. Stevens LJ, Page-McCaw A. A secreted MMP is required for reepithelialization during wound healing. Mol Biol Cell. 2012; 23: 1068-79.

19. Mulero MC, Bigas A, Espinosa L. IkappaBalpha beyond the NF-kB dogma. Oncotarget. 2013; 4: 1550-1.

20. Zhao W, Sun Z, Wang S, Li Z, Zheng L. Wnt1 Participates in Inflammation Induced by Lipopolysaccharide Through Upregulating Scavenger Receptor A and NF-kB. Inflammation. 2015; 38: 1700-6.

21. Chen S, Zhu J, Chen G, Zuo S, Zhang J, Chen Z, et al. 1,25-Dihydroxyvitamin D3 preserves intestinal epithelial barrier function from TNF-alpha induced injury via suppression of NF-kB p65 mediated MLCK-P-MLC signaling pathway. Biochem Biophys Res Commun. 2015; 460: 873-8.

22. Hayden MS, Ghosh S. NF-kappaB in immunobiology. Cell Res. 2011; 21: 223-44.

23. Zhou D, Yu T, Chen G, Brown SA, Yu Z, Mattson MP, et al. Effects of NF-kappaB1 (p50) targeted gene disruption on ionizing radiation-induced NF-kappaB activation and TNFalpha, IL-1alpha, IL-1beta and IL-6 mRNA expression in vivo. Int J Radiat Biol. 2001; 77: 763-72.

24. Na J, Lee $\mathrm{K}, \mathrm{Na} W$, Shin JY, Lee MJ, Yune TY, et al. Histone H3K27 Demethylase JMJD3 in Cooperation with NF-kappaB Regulates Keratinocyte Wound Healing. J Invest Dermatol. 2016; 136: 847-58.

25. Ishida $Y$, Kondo $T$, Kimura A, Matsushima $K$, Mukaida N Absence of IL-1 receptor antagonist impaired wound healing along with aberrant NF-kappaB activation and a reciprocal suppression of TGF-beta signal pathway. J Immunol. 2006; 176: 5598-606. 
26. Rapanan JL, Pascual AS, Uppalapati CK, Cooper KE, Leyva KJ, Hull EE. Zebrafish keratocyte explants to study collective cell migration and reepithelialization in cutaneous wound healing. J Vis Exp. 2015; 96

27. Safferling K, Sutterlin T, Westphal K, Ernst C, Breuhahn K, James M, et al. Wound healing revised: a novel reepithelialization mechanism revealed by in vitro and in silico models. J Cell Biol. 2013; 203: 691-709.

28. Souza BR, Cardoso JF, Amadeu TP, Desmouliere A, Costa AM. Sympathetic denervation accelerates wound contraction but delays reepithelialization in rats. Wound Repair Regen. 2005; 13: 498-505.

29. Bergers G, Brekken R, McMahon G, Vu TH, Itoh T, Tamaki K, et al. Matrix metalloproteinase- 9 triggers the angiogenic switch during carcinogenesis. Nat Cell Biol. 2000; 2: 737-44.

30. Yu Q, Stamenkovic I. Cell surface-localized matrix metalloproteinase-9 proteolytically activates TGF-beta and promotes tumor invasion and angiogenesis. Genes Dev. 2000; 14: 163-76.

31. Parks WC, Wilson CL, Lopez-Boado YS. Matrix metalloproteinases as modulators of inflammation and innate immunity. Nat Rev Immunol. 2004; 4: 617-29.

32. Gill SE, Parks WC. Metalloproteinases and their inhibitors: regulators of wound healing. Int J Biochem Cell Biol. 2008; 40: 1334-47.

33. Villa MM, Wang L, Rowe DW, Wei M. Effects of cell-attachment and extracellular matrix on bone formation in vivo in collagen-hydroxyapatite scaffolds. PloS one. 2014; 9: e109568. 